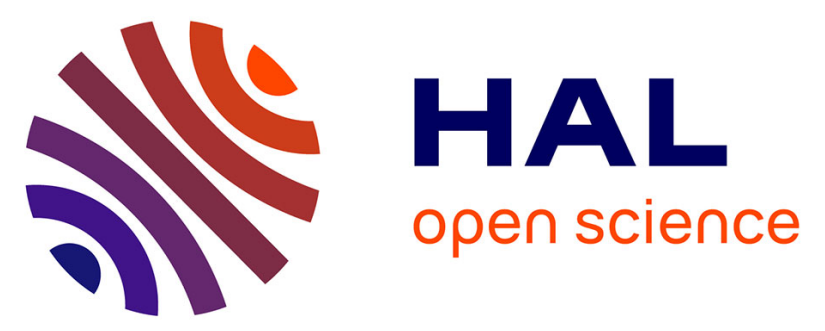

\title{
Evaluation of multiple stress corrosion crack interactions by in-situ Digital Image Correlation
}

J. Bolivar, Marion Fregonese, Julien Réthoré, C. Duret-Thual, P. Combrade

\section{To cite this version:}

J. Bolivar, Marion Fregonese, Julien Réthoré, C. Duret-Thual, P. Combrade. Evaluation of multiple stress corrosion crack interactions by in-situ Digital Image Correlation. Corrosion Science, 2017, 128, pp.120-129. 10.1016/j.corsci.2017.09.001 . hal-01804252

\section{HAL Id: hal-01804252 \\ https://hal.science/hal-01804252}

Submitted on 6 Apr 2021

HAL is a multi-disciplinary open access archive for the deposit and dissemination of scientific research documents, whether they are published or not. The documents may come from teaching and research institutions in France or abroad, or from public or private research centers.
L'archive ouverte pluridisciplinaire HAL, est destinée au dépôt et à la diffusion de documents scientifiques de niveau recherche, publiés ou non, émanant des établissements d'enseignement et de recherche français ou étrangers, des laboratoires publics ou privés. 


\title{
Evaluation of multiple stress corrosion crack interactions by in-situ Digital Image Correlation
}

\author{
J. Bolivara ${ }^{\mathrm{a}}$, M. Frégonèse ${ }^{\mathrm{a}, *}$, J. Réthoré $^{\mathrm{b}}$, C. Duret-Thual ${ }^{\mathrm{c}}$, P. Combrade ${ }^{\mathrm{d}}$ \\ a INSA de Lyon, Université de Lyon, Laboratoire MATEIS UMR 5510, 21 avenue Jean Capelle, 69621 Villeurbanne cedex, France \\ b INSA de Lyon, Université de Lyon, LaMCoS UMR 5259, 27 avenue Jean Capelle, 69621 Villeurbanne cedex, France \\ ${ }^{\mathrm{c}}$ Institut de la Corrosion, ZA du Parc, Secteur Gampille, 42490 Fraisses, France \\ d ACXCOR, 63 chemin de l'Arnica, 42660 Le Bessat, France
}

Digital Image Correlation (DIC), Acoustic Emission and Electrochemical Noise measurements were applied to study the growth of multiple intergranular cracks as a colony on an Alloy 600 in a tetrathionate solution. Cracks exceeding $55 \mu \mathrm{m}$ in length and $0.45 \mu \mathrm{m}$ in opening were successfully detected by DIC. Moreover, crack popu-lation was classified into initiating, active and dormant cracks, active population being the larger one. The emergence and intensification of interactions produced a modification on the colony growth behavior. They range from a mostly surface crack propagation (in the absence of interactions), to in depth propagation pre-dominantly governed by crack shielding.

\section{Introduction}

Stress Corrosion Cracking (SCC) is a premature degradation process of metals and alloys generated by the synergistic effect of static mechanical loading and environmental factors [1]. As such, SCC represents a common localized corrosion issue in industries operating under extreme conditions, especially in nuclear power plants (e.g. the primary cooling circuit) [2-4]. Most nuclear reactors around the world were designed to operate for $30-40$ years and are actually reaching the average age of 30 years $[5,6]$. In this context, much of the safety assessments concerning SCC risk have over-simplified some stages in the aging process, such as initiation and the periods of interactions between several cracks (e.g. shielding effects, coalescence and irregular propagation) [7-11]. Therefore, the predicted lifetime is often over-conservative, as the initiation stages and the interaction periods play a considerable role in the cracking process [12]. Subsequently, current trends indicate that the lifetime of certain structures is extended by as much as possible, until the next reactors are constructed (i.e. IV generation) [3-4,13]. The latter implies a better understanding of the growth behavior of multiple cracking, which is modified by both initiation kinetics and crack interactions, in order to adapt the prevailing models.

A crack colony is defined by an assembly of cracks sharing a wellconfined surface. Individual cracks in the colony exhibit irregular growth behavior controlled by crack interactions. Such mechanical interactions between cracks result from the reorganization of the stress field ahead of the different cracks tips (stress concentration) and crack flanks (stress shielding) [14]. Interactions considerably affect the individual crack growth rate and turn the study of multiple cracking into a challenging problem. However, the multiple cracking phenomenon is not only related to SCC issues [15]. It is also observed in the fatigue field (fatigue, corrosion fatigue and thermal fatigue) also due to the existence of multiple initiation sites [16-20].

Analytical and experimental analyses have been recently carried out in both domains. In numerical analysis, interactions are usually studied under Linear Elastic Fracture Mechanics (LEFM) for which the local stress conditions near the crack tip are defined by the Stress Intensity Factor (SIF). Interaction effects have been studied by calculating the evolution of the SIF for a couple of neighboring cracks by using the Body Force Method (BFM) and Finite Element Modelling (FEM) [21-26]. A consensus in the results shows that the SIFs values in the vicinity of the approaching crack tips are magnified and cause acceleration in the crack growth [15]. Despite this, in the cases of overlapping crack tips, the interaction level decreases due to the shielding effect [22]. After several numerical simulations, Kamaya et al. attributed the different behaviors to the high dependency of the SIF magnitude against the relative position, the relative sizes and crack shape [27]. Furthermore, they proved that the intensity of the interactions varies across the position in the crack front of a 3D semi-elliptical crack. The SIF values are therefore higher at the surface approaching crack

\footnotetext{
* Corresponding author.

E-mail address: marion.fregonese@insa-lyon.fr (M. Frégonèse).
} 
tips than in the middle point of each crack in the depth direction [28].

Nevertheless, the high crack densities observed in a crack colony limit such numerical analysis in the case of 3D simulations. In contrast, experimental approaches based on the indirect evaluation of SIF-values remain attractive and manageable in the case of multiple cracking $[9,22,27]$. Such observations deal principally with the study of crack interactions as a function of crack parameters as length, crack opening, offset distance, crack growth rate and coalescence events. Wang et al. used an ex-situ approach based on interrupted tests in order to study multiple cracking [9]. They evaluate the influence of interactions on crack growth by measuring the evolution of the crack parameters. They highlighted the importance of the mixed loading conditions (modes I and II) in the vicinity of the approaching crack tips. In addition, they collected multiple data concerning initiation kinetics and the localization of cracks with regard to modeling the multiple SCC process $[12,29]$. Notwithstanding, although ex-situ observations provide crucial information, in-situ observations display more suitable characteristics for SCC studies. Yet direct access to the sample must avoid the variations in testing conditions which may deeply interfere with the SCC process [30].

In this context, several studies have shown some advantages of Digital Image Correlation (DIC) for studies devoted to cracking [31-34]. DIC has been widely used in the fracture mechanics field due to its simplicity and high resolution capabilities. This technique allows the measurements of full/local field strain by comparing an image, corresponding to a deformed state, to one that corresponds to a reference state. The appearance of discontinuities in the surface (e.g. cracks) is easily identified by a jump in the displacement field facilitating the early identification of crack initiation. Some studies have already applied DIC to SCC experiments [35-39]. Cook et al. were the first to implement DIC to SCC studies [40]. They detected and quantified the growth of a few cracks at room temperature, in a $304 \mathrm{~L}$ stainless steel with a detection resolution of $250 \mu \mathrm{m}$ in length and an opening of $5 \mu \mathrm{m}$. Today, improvements in the technique make it possible to identify cracks larger than $30 \mu \mathrm{m}$ in length and opened more than $1 \mu \mathrm{m}$ without decreasing the size of the Region Of Interest (ROI). These detection limits are advantageous in contrast to classic image analysis where very narrow cracks (initiation stages) could be difficult to detect.

In addition, some authors coupled DIC with complementary techniques such as Acoustic Emission (AE) and Electrochemical Noise (EN) in order to increase the monitoring capabilities of the SCC process, especially the sequence of electrochemical and mechanical events [41-44]. The EN technique is based on the measurement of current and potential fluctuations, generated by electrochemical processes such as corrosion reactions. One variant of the technique allows us to measure both the current and potential at the open circuit potential, classifying the method as non-intrusive. Between the several applications of EN, the possibility and sensitivity to detect the initiation process of cracking must be cited. Several investigators have already reported the relation between crack initiation and EN measurements in different systems $[45,46]$. Their results were discussed on the base of the slip dissolution model and the film-rupture model. The dissolution of the bare surface generated during the initiation process or the propagation of the crack tip, generates positive current transients and negative potential fluctuations. The shape of these transients was of particular interest $[47,48]$ during the propagation of one or multiple cracks. Breimesser et al. [48] registered three different transients during an SCC test in a notched specimen. They attributed the three different fluctuations to metastable pitting, propagation of single cracks and coalescence events. The superposition of transients, coming from different propagation steps simultaneously, produces the apparition of a DC level. Kovac et al. [44] showed that the DC part of the Electrochemical Current Noise (ECN) increases with the intensification of the dissolution process. In addition, the DC part showed high correlation with the anodic area generated by the active cracks. In contrast, Breimesser et al. [46] related the charge associated with current transients to the individual crack propagation step, with the volume of metal dissolution due to the crack tip advance through the Faraday relation.

On the other hand, Acoustic Emission is known for its great ability to detect the evolution damage in different materials $[49,50]$. This technique is based on the detection of elastic acoustic waves, released by the fast energy relaxation of an irreversible localized damage phenomenon. AE have been widely used in SCC studies due to the energetic character of SCC and the numerous sources of AE activity that participate in the process [51]. Several authors have already used the evolution of AE activity in order to detect crack initiation and/or monitoring crack propagation. Indeed, the acoustic emission activity increases as cracks initiate and propagate. Moreover, other studies have centered the attention on the characteristics of acoustic events. Different sources of $\mathrm{AE}$ produce waves exhibiting distinctive $\mathrm{AE}$ parameters. Among the sources, the rupture of the oxide film, the dissolution of metal, $\mathrm{H}_{2}$ gas evolution (related to pitting), plastic deformation of the crack tip, the fracture of ligaments and crack propagation can be cited. The classification of such events into their different nature, has given us lots of information on the cracking mechanism. For example, the distinction between continuous or discontinuous cracking, intergranular or transgranular cracking and the initiation or propagation of cracks can be obtained. [43,52-55].

The present study aims to develop a methodology based on DIC, AE and EN techniques for characterizing the behavior of an SCC colony considering the individual evolution of each crack. The synergic use of these three techniques is expected to allow the reliable detection, monitoring and study of Intergranular Stress Corrosion Cracking (IGSCC). Attention will be focused on identifying the different stages of the crack colony evolution and the mechanisms involved in each stage. Specific parameters will be defined for this purpose.

\section{Experimental procedure}

\subsection{Material and sample preparation}

The tested material consisted of a $2 \mathrm{~mm}$ thick plate of Alloy 600, whose chemical composition is given in Table 1 . The specimens were machined out by Electrical Discharge Machining with a gauge length of $117 \mathrm{~mm}$ and a width of $8 \mathrm{~mm}$ (Fig. 1a). The samples underwent a full sensitization heat treatment $\left(30 \mathrm{~h}\right.$ at $600{ }^{\circ} \mathrm{C}$ and air-cooled) to obtain the precipitation of carbides at the grain boundaries in order to increase susceptibility of IG-SCC of the alloy (in a tetrathionate solution at room temperature). The resulting microstructure exhibits an austenitic matrix with a grain size of $70-100 \mu \mathrm{m}$. Prior to testing, the sample surfaces were prepared by grinding up to 1200 grit SiC paper, and then electroetched in a solution of $8 \mathrm{vol} \%$ perchloric acid and $92 \mathrm{vol} \%$ glacial acetic acid in two stages: at $5 \mathrm{~V}$ for $30 \mathrm{~s}$, and then $10 \mathrm{~V}$ for $1 \mathrm{~min}$. This surface treatment produces a very shallow and random heterogeneous pattern, suitable for further DIC analysis.

In order to reduce the exposed surface, the specimens were partially covered with silicon rubber. Both sides of the middle section of the samples were exposed to the electrolyte, each with an exposed area of $120 \mathrm{~mm}^{2}(15 \times 8 \mathrm{~mm})$. The experiments were performed in a three electrode cell test with optical access for DIC measurements (Fig. 1b). For all the experiments, the test solution consisted of $0.01 \mathrm{M}$ potassium tetrathionate acidified at $\mathrm{pH} 3$ by $\mathrm{H}_{2} \mathrm{SO}_{4}$ addition.

Table 1

Composition of by tested Alloy 600

\begin{tabular}{llllllllll}
\hline Element & $\mathrm{Ni}$ & $\mathrm{Fe}$ & $\mathrm{Cr}$ & $\mathrm{Mn}$ & $\mathrm{Cu}$ & $\mathrm{Co}$ & $\mathrm{Ti}+\mathrm{Al}$ & $\mathrm{C}$ & $\mathrm{S}$ \\
\hline Wt.\% & bal. & 9,25 & 15,52 & 0,12 & 0,1 & 0,1 & 0,25 & 0,03 & 0,002 \\
\hline
\end{tabular}




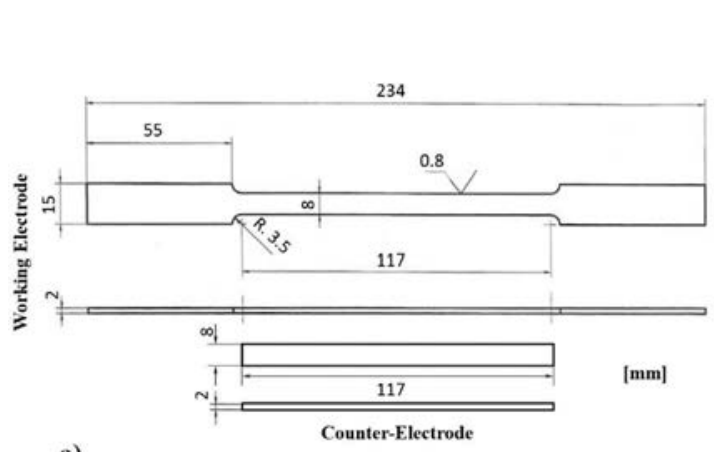

a)

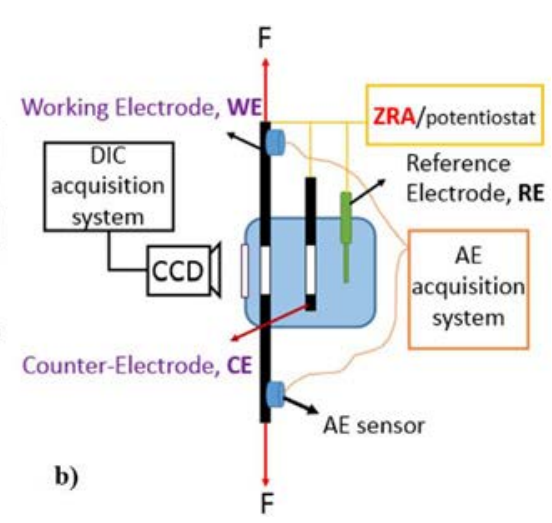

Fig. 1. Diagram of the experimental device: a) geometry of specimens and counter-electrodes and b) schematic picture of the experimental device.

\subsection{SCC test and monitoring techniques}

Constant load tests were carried out at $80 \%$ of the yield stress (263 MPa) using an electromechanical tensile machine (LLOYD LR30K Plus). Samples were immersed in the test solution $60 \mathrm{~min}$ before loading began. The tests which were not executed until rupture, were interrupted when a representative colony of cracks was detected by visual observation and when the Open Circuit Potential (OCP) of the specimen was stabilized at around $-195 \mathrm{mV} / \mathrm{SCE}$. At the end of the test, the samples were examined either by Optical Microscopy (OM) or Scanning Electron Microscopy (SEM) in order to validate the identification of cracks.

All tests were monitored by three different measurement techniques. Electrochemical Noise (EN) was measured in a freely corroding system between three electrodes. The Working Electrode (WE) and the Counter-Electrode (CE) were made from the same material and had the same surface treatment. They were positioned in parallel and approximately $1 \mathrm{~cm}$ apart. The reference electrode was a Saturated Calomel Electrode (SCE). The Electrochemical Potential Noise (EPN) and Current Noise (ECN) were acquired and recorded by a GAMRY potentiostat (ESA410 software) with a sampling frequency of $10 \mathrm{~Hz}$.

The acoustic emission (AE) was acquired using two piezoelectric $\mathrm{AE}$ sensors R15D: one was fixed to the top of the working electrode (stressed specimen), the second one was fixed to the bottom of it (Fig. 1b). The operating frequencies of the sensors were between 20 and $1000 \mathrm{kHz}$ with a resonance frequency centered on $150 \mathrm{kHz}$. The sensor out-put was amplified by a gain of $60 \mathrm{~dB}$. The sampling frequency was $2 \mathrm{MHz}$. Furthermore, two frequency filters were used: a high-pass filter with a cutoff frequency of $100 \mathrm{kHz}$ and a low-pass filter with a cutoff frequency of $400 \mathrm{kHz}$. The threshold was $23 \mathrm{~dB}$, which was slightly above the background noise.

The sample surface was observed through a $2 / 3$ "inch" CCD Stingray 5 megapixel camera with a pixel size of $3.45 \mu \mathrm{m}$. The camera was coupled with a $1 \mathrm{X}$ telecentric lens. The surface was lit with a led lamp in order to eliminate night and day light variation. Two polarizing filters were also used in the lamp and in the lens respectively in order to limit light reflection.

DIC analysis was carried out using an in-house developed software based on finite elements [56]. Square elements with a size of 16 pixels $(55 \mu \mathrm{m})$ were used for displacement vector assessment. Images were recorded every $60 \mathrm{~s}$. Crack identification was achieved by detecting the displacement jump originated by the crack opening in the displacement field. Fig. 2a represents this displacement field. The amplitude of the discontinuity caused by the crack detection directly represents the opening value of the crack. In order to clarify the discontinuities, Rigid Body Movement (RBM) and the homogenous mean strain were extracted from the displacement fields. Additionally, the resulting field was differentiated in the y-axis and subsequently multiplied by the element size. Thereby a displacement jump field could be obtained. Fig. $2 \mathrm{~b}$ represents the resulting filtered field. Then, cracks were identified by segmenting the field with a threshold (Fig. 2c), which corresponds to the uncertainty of measurements $(0.45 \mu \mathrm{m})$. The segments of elements with a displacement jump bigger than the threshold, and obeying a connectivity of 8 (considering that an element can have contact with one of its 8 neighbors) leads to crack detection. Finally, the cracks were labelled and their parameters (length, opening, Crack Growth Rate (CGR) and dynamic state, etc.) were extracted.

\section{Results}

\subsection{General behavior of the crack colony}

Four room temperature SCC constant load tests were performed in a $10 \mathrm{mM} \mathrm{K}_{2} \mathrm{~S}_{4} \mathrm{O}_{6}$ (acidified to $\mathrm{pH}$ 3) solution and loaded to $80 \%$ of the yield stress. The immersion time before loading was in the range of 1-24 h. Table 2 gathers the main results. The zero time was defined at the moment when the samples were loaded. It may be noted that the crack initiation time $\left(t_{a}\right)$ is, as expected, influenced by the duration of the previous immersion stage. After $4 \mathrm{~h}$ of pre-immersion, the crack initiation time decreases as the pre-immersion time increases. Yet, the evolution of the crack colony remains equivalent for all the tests. It is characterized by the development of multiple cracks by IGSCC with short incubation periods and high crack densities. For the presentation of further analysis, only the CC 03-15 experiment is explained in detail next. It exhibits features representative of the four tests.

Fig. 3 presents the evolution of the crack density for the CC 03-15 test together with the stress and strain measurements. Once the stress of interest is reached (210 MPa), the mean strain obtained by DIC remains very low $(0.1 \%)$. Soon after, a sudden increase appears at $378 \mathrm{~min}\left(t_{a}\right)$ which occurs when the first surface crack is detected. Subsequently, initiations become more and more assiduous and a multiple cracking regime is established. Moreover, the crack density evolution shows an increase with a slope " $m$ " (" $m$ " is the number of cracks per unit of surface and time, see Table 2) until a maximum at time $t_{b}$ is reached. Then, the behavior changes and crack density decreases due to competition between the initiation kinetics and coalescence rate.

\subsection{Crack colony morphology}

Fig. 4 presents selected images captured either by the digital imaging system or by SEM analysis after test. They illustrate the characteristics of the obtained crack colonies. Fig. 4a was obtained at the final stage of the test and shows the morphology of the crack colony. Several cracks exhibit highly brittle characteristics associated with an intergranular path. The fractography presented in Fig. $4 \mathrm{~b}$ confirms the intergranular nature of the fracture (Fig. 4c). Moreover, the high density of the cracks and the reduced space between them favors the emergence of interactions. An example of such can be seen in Fig. 4c, where some cracks coalesce while others reveal crack tip deviation. 


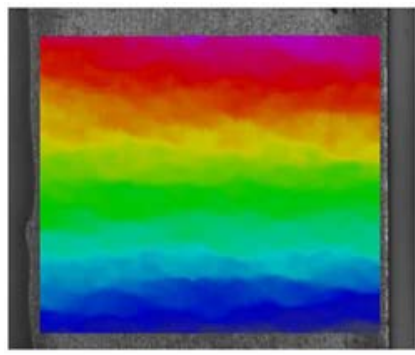

a)

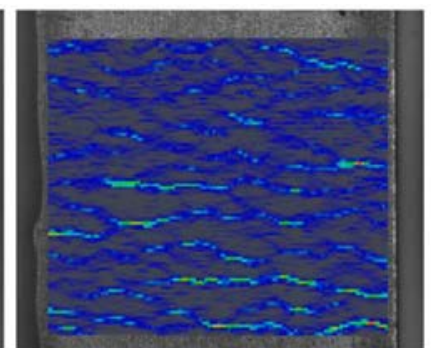

b)

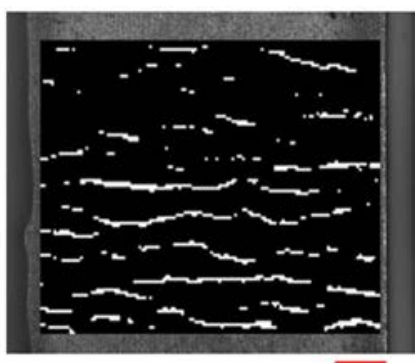

c)

$\overline{1 \mathrm{~mm}}$
Fig. 2. Procedure for the identification of a crack by DIC analysis: a) displacement field; b) filtered displacement field and c) binary field.
Table 2

Crack density values and characteristic times for constant load tests conducted in $10 \mathrm{mM}$ potassium tetrathionate at $\mathrm{pH} 3$ with different pre-immersion times.

\begin{tabular}{llllll}
\hline ID test & $\begin{array}{l}\text { Immersion } \\
\text { time before } \\
\text { loading }(h)\end{array}$ & $\begin{array}{l}\text { Crack } \\
\text { initiation } \\
\left(t_{a}, \mathrm{~min}\right)\end{array}$ & $\begin{array}{l}\text { Maximal } \\
\text { crack } \\
\text { density } \\
\left(\frac{\mathrm{cracks}}{\mathrm{cm}^{2}}\right)\end{array}$ & $t_{b}(\mathrm{~min})$ & $m\left(\frac{\mathrm{cracks}}{\mathrm{min}^{*} \mathrm{~cm}^{2}}\right)$ \\
\hline $\mathrm{CC}-02-15$ & 4 & 493 & 232 & 763 & 1.36 \\
$\mathrm{CC}-03-15$ & 1 & 378 & 240 & 830 & 1.37 \\
$\mathrm{CC}-01-15$ & 5 & 187 & 307 & 712 & 1.43 \\
CC-05-15 & 24 & 71 & 169 & 391 & 1.45 \\
\hline
\end{tabular}

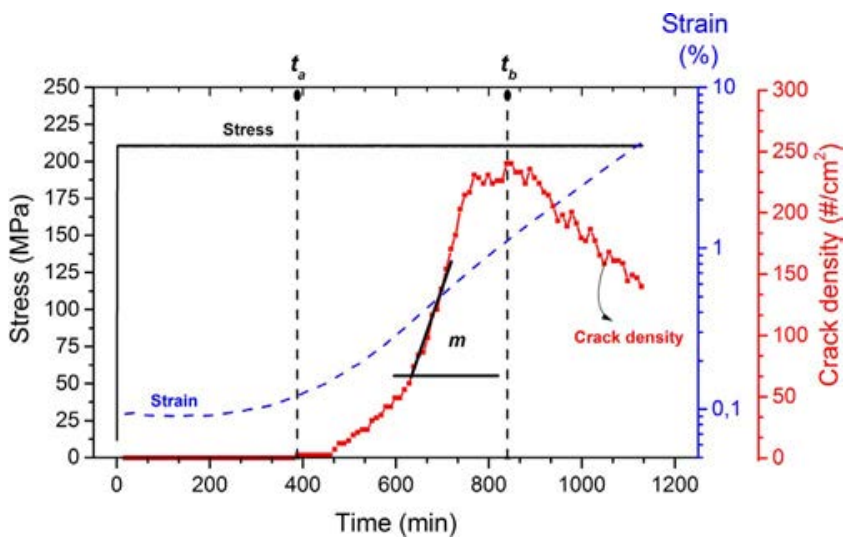

Fig. 3. Crack density and strain evolution during the SCC test CC 03-15.

\subsection{Crack detection}

Detecting and localizing the cracks was easily achieved even when the cracks propagated under a very narrow path with an opening displacement that remains in the order of a hundred nanometers. The detection limits for the crack identification were $55 \mu \mathrm{m}$ in length and $0.45 \mu \mathrm{m}$ in opening. The former limitation is due to the size of the elements used for DIC assessment ( 16 pixel $\times 16$ pixel) and the second is associated with the accuracy of the measurements, mainly related to noise (e.g liquid convection, speckle pattern quality, etc.). Fig. 5 shows some optical images obtained during the SCC test with their respective
post-DIC assessments. At $630 \mathrm{~min}$ (Fig. 5a), the DIC analysis reveals the presence of few cracks in an initiation stage while, due to the very low opening of the cracks it remains almost impossible to detect them by the simple analysis of the images recorded by the CCD camera. This difficulty is also encountered when the crack colony reaches the maximal crack density (Fig. 5b). Fig. 5c represents a CCD picture taken at 1130 min when a few cracks start to present a predominant macro individual behavior. This is related to the final phase of the crack colony growth and is not within the framework of this study.

\subsection{Crack population, interactions and global growth behavior}

Each crack detected at time $t_{i}$ is labelled. Labels are gradually incremented when new cracks are detected (Fig. 6). When two cracks coalesce the resulting crack keeps the lowest value of the label (i.e. the one of the most ancient crack).

Moreover, the crack populations were classified according to the different dynamic states and are defined as active, dormant and initiating cracks. A crack is called active at a time $t_{i}$ when its length and/ or its opening has increased between times $t_{i-1}$ and $t_{i}\left(t_{i}-t_{i-1}\right.$ corresponds to the interval of time between 2 successive images (i-1) and (i) analyzed by DIC). A crack is called dormant at a time $t_{i}$ when its length and its opening have not increased between times $t_{i-1}$ and $t_{i}$. Indeed, LEFM indicates that if no variation in the opening or in the length is observed, the crack depth remains also constant. If a new crack initiates between $t_{i-1}$ and $t_{i}$, it is counted as a new initiation event at $t_{i}$, but it is not yet considered as active. If its length and/or its opening vary between $t_{i}$ and $t_{i+1}$, it will be considered as active at $t_{i+1}$. One example is schematized in Fig. 6 . In this example cracks 1 and 2 coalesce and give crack 1 at time $t_{i}$; crack 1 is then classified as active at time $t_{i}$. Crack 3 exhibits the same length and opening as at time $t_{i-1}$, therefore it is considered as a dormant crack. Finally, crack 4 is detected at time $t_{i}$ and is designated as an initiation.

Fig. 7 shows an example of how some dormant and active cracks evolve for the CC-03-15 test. It can be seen that crack "2" exhibits a period of dormancy between 450 and $750 \mathrm{~min}$, whereas, cracks "91" and "102" show active behavior from their initiation. Both cracks ("91" and "102") initiate and propagate until a phenomenon of coalescence takes place, when crack " 102 " merged with crack " 91 " and is registered as a discontinuity in both length measurements.

For test CC 03-15, a total of 307 cracks were labelled all along the test (Table 3). At the end of the test 65 cracks were still present, which

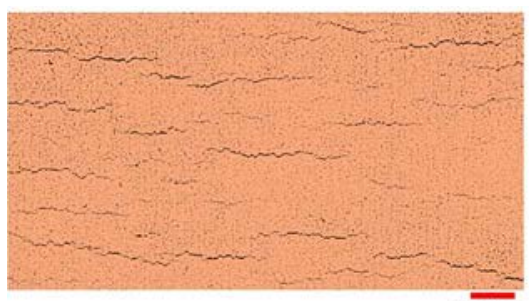

a)

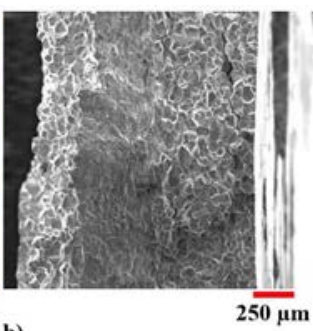

b)

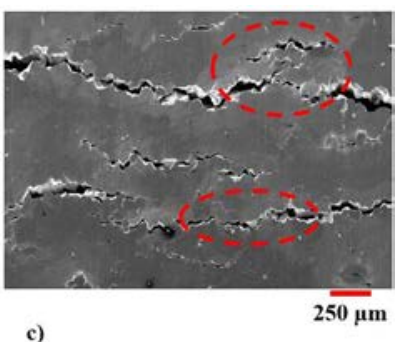

c)
Fig. 4. Typical morphology of the crack colonies obtained. a) CCD image obtained at the end of an interrupted test at $1130 \mathrm{~min}$ (CC-03-15). b) SEM fractography after in-situ rupture of the specimen CC-02-15 and c) SEM image of the CC-03-15 sample surface. 

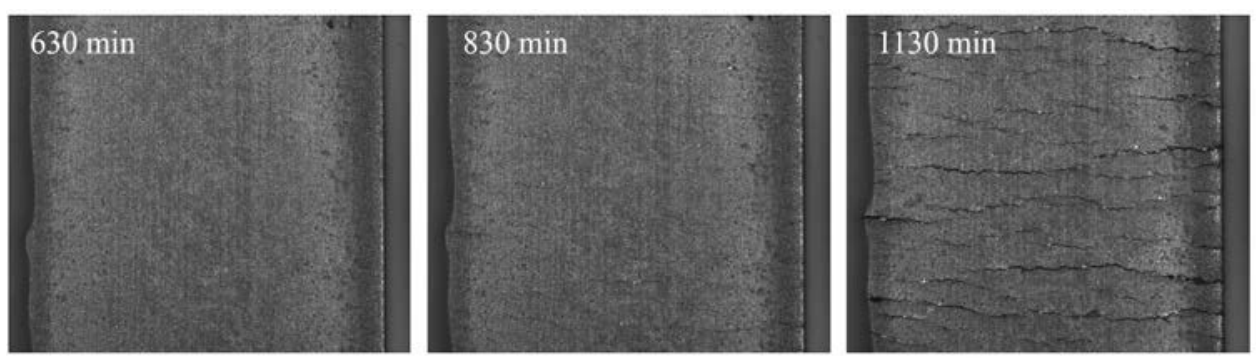

Fig. 5. DIC analysis after a SCC test conducted at constant load (CC 03-15): CCD images and filtered displacement field including crack labelling. a) at $630 \mathrm{~min}$; b) at $830 \mathrm{~min}\left(\right.$ time $\mathrm{t}_{\mathrm{b}}$ ) and c) at $1130 \mathrm{~min}$.

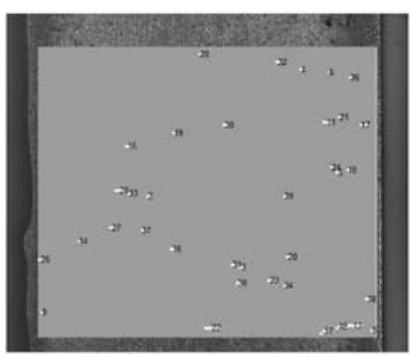

a)

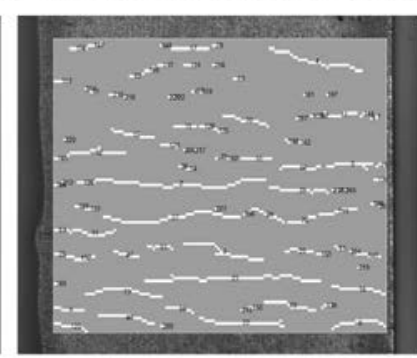

b)

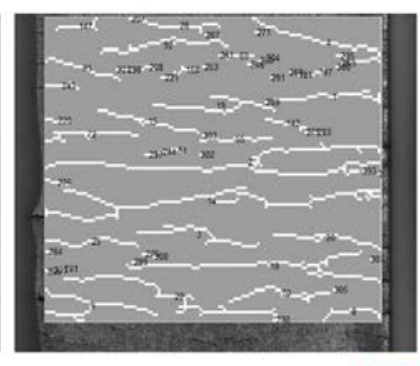

c)
$1 \mathrm{~mm}$ means that 242 coalescences occurred. At time $t_{b}$, the number of cracks was maximum (Fig. 3).

For each step of image treatment, the mean crack length, mean crack opening and coalescence events can be obtained. The evolution of these parameters is presented in Fig. 8. Both mean crack length and mean crack opening exhibit a continuous increase from time $t_{a}$ all along the test, with acceleration at about $700 \mathrm{~min}$. On the other hand, the number of coalescence events starts to increase at $658 \mathrm{~min}\left(t_{c}\right)$, then remains globally constant after time $t_{b}$ corresponding to the maximum crack density detection (Table 2). Individual crack growth rate (CGR) can be defined as the difference in length between two subsequent images divided by the span time and was calculated for each crack. A mean value of the CGR was also calculated for the active cracks without taking into account newly initiated cracks nor active cracks involved in coalescence events; its evolution is also depicted in Fig. 8. The mean CGR shows a minor increase from $t_{a}$ until $t_{c}$, then, it remains almost constant between $t_{c}$ and $t_{b}$. Finally, it displays a slight decrease from $t_{b}$ until the end of the test.

Fig. 9 plots the distribution of each kind of crack (active, dormant and initiation) during the whole SCC test. It can be noted that the active cracks are in the majority throughout the test, followed by the dormant cracks and the number of cracks that initiate at each step. The total number of cracks at time $t_{i}$ is the sum of the active, dormant and newly initiated crack numbers; the active crack number includes the coalescence events.

From these observations, it can be assessed that between times $t_{a}$ and $t_{c}$ the global number of cracks increases due to the increase of newly initiated cracks and the absence of coalescence events (Fig. 8). In this first part of colony life, both active and dormant cracks follow the same increasing evolution. From time $t_{c}$, the population of active cracks becomes predominant, whereas dormant and newly initiated cracks continue to increase. At the same time, the number of coalescence events sharply increases (Fig. 8). At time close to $t_{b}$, the coalescence kinetics slows down together with the number of initiation events. However, as the number of coalescence events remains higher than the number of initiation events, the global crack density decreases.

Furthermore, an aspect ratio " $\eta$ " was calculated. It consists of the ratio of the depth " $d$ " to the half-length " $c$ " of each crack (Eq. (1)). The " $\eta$ " factor aims at describing the evolution in time of the crack shape and also the impact of the intensification of interactions on crack propagation. The " $\eta$ " factor was obtained for each crack by resolving Eq. (3), which derives from Eq. (2). The terms $\sigma$ (in Pa), $v$ and $E$ (in Pa) represent the loading stress, Poisson's ratio and the Young's modulus of the material respectively. Eq. (2) was proposed by Hack [57] and describes the opening " $a$ " (expressed in meters, so as " $d$ " and "c") of a crack by using a closed linear elastic crack-tip solution for a semi-elliptical crack in a finite plate under tension. The authors are aware that Eq. (2) is only valid within the frame of the LEFM, which requires few plastic deformation confined at the crack tips. In these experiments, the cracking mechanism was very brittle and such deformation could be considered as negligible during the most part of the experiment. As such, a decreasing " $\eta$ " indicates surface propagation, while an increasing " $\eta$ " is the indication of a crack propagating in depth.

$\eta=\frac{d}{c}$

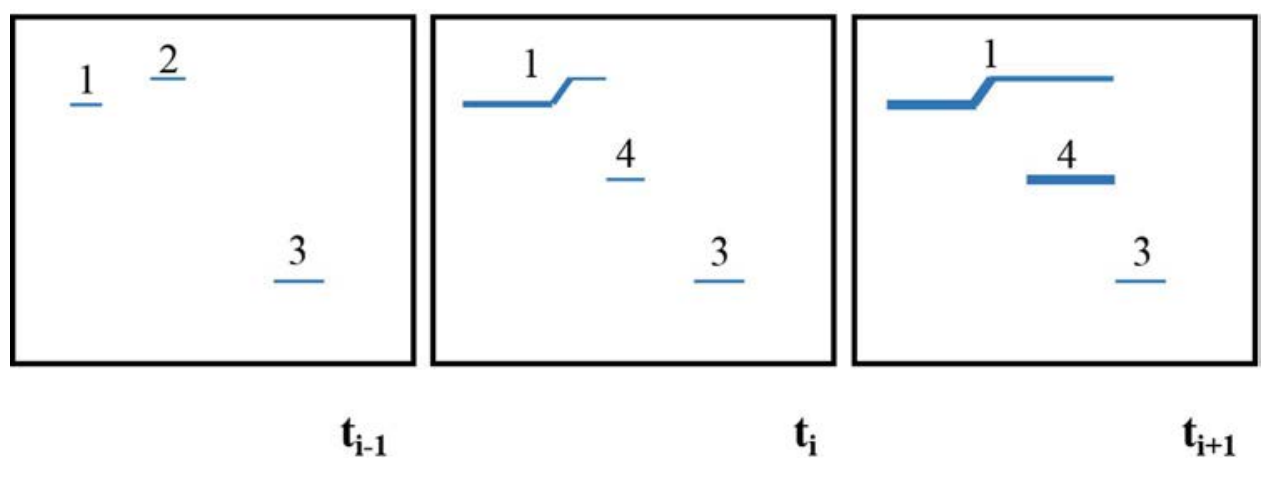

Fig. 6. Diagram showing the classification of the dynamic states of cracks at a time $t_{i}$. 


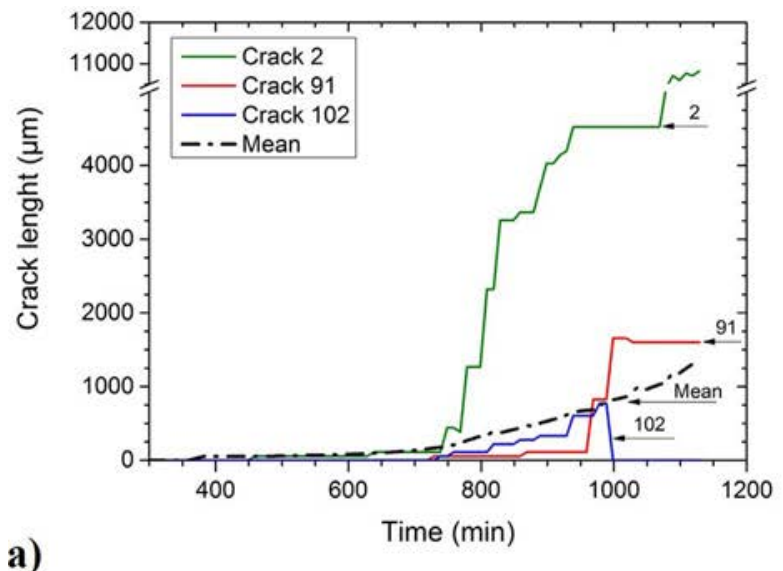

a)

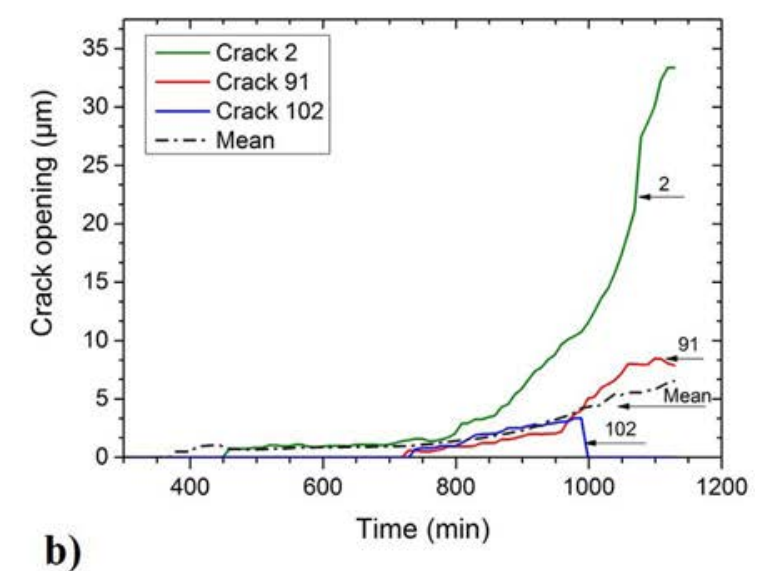

Fig. 7. Extraction of crack parameters through the SCC test. a) Crack length b) Crack opening.

Table 3

Number of cracks at the maximum of crack density $\left(t_{b}\right)$ and at the end of the test CC 0315.

\begin{tabular}{llllll}
\hline & At time $\mathrm{t}_{\mathrm{b}}(830 \mathrm{~min})$ & \multicolumn{2}{l}{$\begin{array}{l}\text { At the end of the test } \\
(1130 \mathrm{~min})\end{array}$} \\
\cline { 2 - 4 } $\begin{array}{l}\text { \# Total } \\
\begin{array}{l}\text { number of } \\
\text { cracks in } \\
\text { ROI }\end{array}\end{array}$ & Cracks (\#) & $\begin{array}{l}\text { Density of } \\
\text { cracks } \\
\left(\# / \mathrm{cm}^{2}\right)\end{array}$ & $\begin{array}{l}\text { Cracks }(\#) \\
\text { Density of } \\
\text { cracks } \\
\left(\# / \mathrm{cm}^{2}\right)\end{array}$ & $\begin{array}{l}\text { Total number } \\
\text { of coalescences }\end{array}$ \\
\hline 307 & 103 & 240 & 65 & 140 & 242 \\
\hline
\end{tabular}

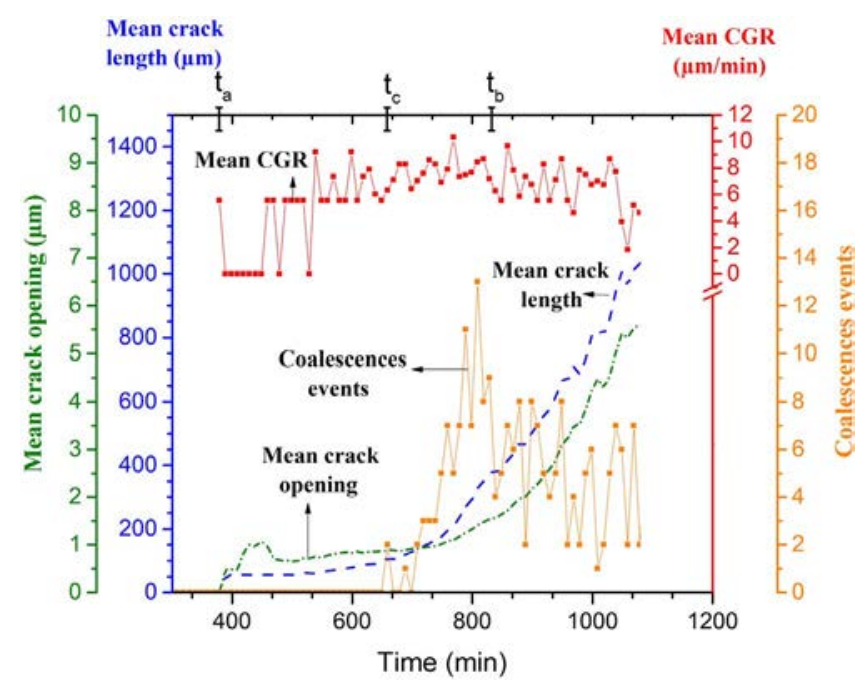

Fig. 8. Coalescence event and evolution of the mean length, mean opening and mean crack growth rate (without taking into account coalescence of cracks) for CC 03-15 SCC test.

$a=4 \sqrt{2}\left(1-v^{2}\right)\left(\sigma \frac{d}{E}\right)\left(1+0.12\left(1-\frac{d}{c}\right)\left(\sqrt{1-0.619 \frac{d}{c}}\right)\right.$

$\frac{a}{c}-\left(\frac{d}{c}\right)\left[4 \sqrt{2}\left(1-v^{2}\right)\left(\frac{\sigma}{E}\right)\left(1+0.12\left(1-\frac{d}{c}\right)\left(\sqrt{1-0.619 \frac{d}{c}}\right)\right]=0\right.$

Fig. 10 presents the evolution of the mean aspect ratio " $\eta$ ", crack density and a growing indicator called Global Crack Colony Growth Rate (GCCGR). The GCCGR is defined as the variation of the cumulative crack lengths in the colony for a step over the time $\left(t_{i}-t_{i-1}\right)$. It may be noted that the mean " $\eta$ " Exhibits 2 stages, suggesting two different

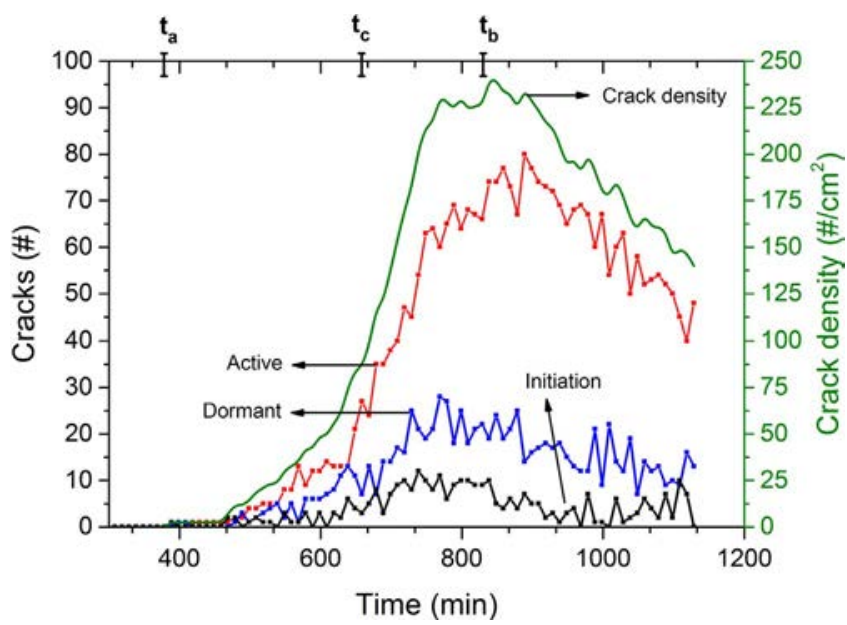

Fig. 9. Distribution of crack populations during the SCC test.

regimes of propagation. One from $t_{a}$ to $t_{b}$ where cracks tend to propagate more on the surface than in depth. Then, around $t_{b}$ there is an inflection point in both curves (" $\eta$ " and global GCCGR). The decrease in the GCCGR and the increase in " $\eta$ " suggest that cracks tend to grow more in depth than on the surface.

\subsection{Acoustic Emission, Digital Image Correlation an Electrochemical Noise measurements during the SCC test}

Fig. 11 gathers AE, EN and DIC results. The active cracks population obtained by DIC is included in the graph. The acoustic emission activity is represented by signal amplitude, each point corresponding to a registered acoustic event. It can be seen that the majority of acoustic activity is detected during the very first part of the test corresponding to the dynamic loading of the specimen, and starts again 900 min into the test. The mean Electrochemical Potential Noise (EPN) and mean Electrochemical Current Noise (ECN) coming from EN measurements are also plotted. They were calculated using blocks of 512 points. The mean EPN displays a continuous drop accompanied by high levels in the DC part of the mean ECN which indicates that anodic reactions are occurring at the Working Electrode (WE). Then stagnation of the EPN is observed at a time when the number of active cracks begins to decrease.

\section{Discussion}

The experimental methodology implemented in this study enabled a crack colony exhibiting different features of interactions such as 


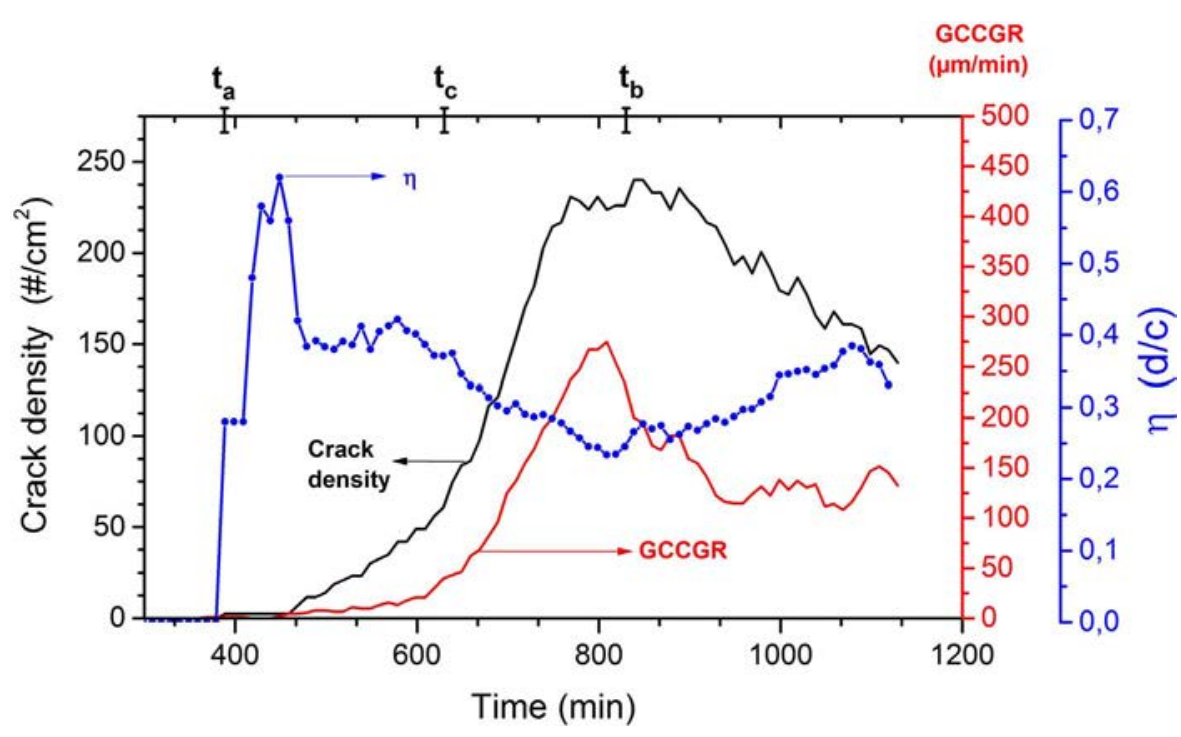

Fig. 10. Evolution of the aspect ratio " $\eta$ ", crack density and global crack growth through the SCC test.

coalescence, dormancy and shielding to initiate and propagate. The experimental methodology was based on constant load tests conducted at $80 \%$ of the yield stress of an Alloy 600 alloy in a tetrathionate acidified solution with AE, DIC and EN monitoring. The obtained cracks presented short incubation times, a brittle aspect, low level of plastic deformation around the crack tips and a mainly intergranular morphology (Fig. 4). These results are in good agreement with studies previously reported. Polythionate acidic solutions such as potassium tetrathionate are known to promote IG-SCC with characteristics similar to those encountered in pressurized water reactor aqueous environments. In this case, IG-SCC is produced at room temperature in a nickel based alloy which was heat sensitized to form chromium rich carbide precipitates at grain boundaries, thereby generating a chromium depleted grain boundary region, which is more anodic than grain boundaries containing chromium carbides [58]. Therefore, cracks initiate on the Cr-depleted areas that present a weak passivity and propagate along the grain boundaries.

Several tests were performed under identical experimental conditions but with differing immersion times before loading. For periods longer than $4 \mathrm{~h}$ of pre-immersion, a decrease in the crack initiation time was noted when the duration of pre-immersion time was increased (Table 2). Indeed, the Alloy 600 alloy is known to suffer an Intergranular Attack (IGA) in polythionate acidic solutions for concentrations up to $0.1 \mathrm{mM}$ [59]. Thereby, it can be assumed that for pre- immersion greater than $4 \mathrm{~h}$, the IGA is deep enough to initiate stress corrosion cracks once a stress is applied. Initiation time is therefore reduced when the pre-immersion time is longer.

For tests undertaken, the crack density exhibits a maximum (Table 2 and Fig. 3). The existence of this maximum (at time $t_{b}$ ) tends to indicate that the competition between initiations contributing to the increase in crack density, and coalescences contributing to its decrease, favor coalescences. In the case of the $24 \mathrm{~h}$ pre-immersed sample, the maximal crack density value is smaller. This result is in agreement with the fact that a longer pre-immersion time induces a more extensive IGA [60]. When the load is applied, more and longer cracks quickly initiate compared to an experiment where initiated cracks are smaller and fewer due to a weaker extension of IGA. Yet, the relaxation zone generated by the emergence of a crack lead to a shielding effect and crack initiation is inhibited inside this zone (Fig. 12), whose extent is proportional to the initiated crack length [23]. Consequently, when the pre-immersion time increases, there are more cracks in the very first stages, yet, as they are also longer due to the extent of IGA, further initiations are inhibited and coalescences are enhanced. Maximum crack density is therefore lowered at the end. Despite these differences, the overall behavior of the crack colony remains the same regardless of the duration of pre-immersion before loading. The latter is confirmed by the global evolution in crack density with similar values of the slope " $m$ " (Table 3) representing the global kinetic evolution of the crack

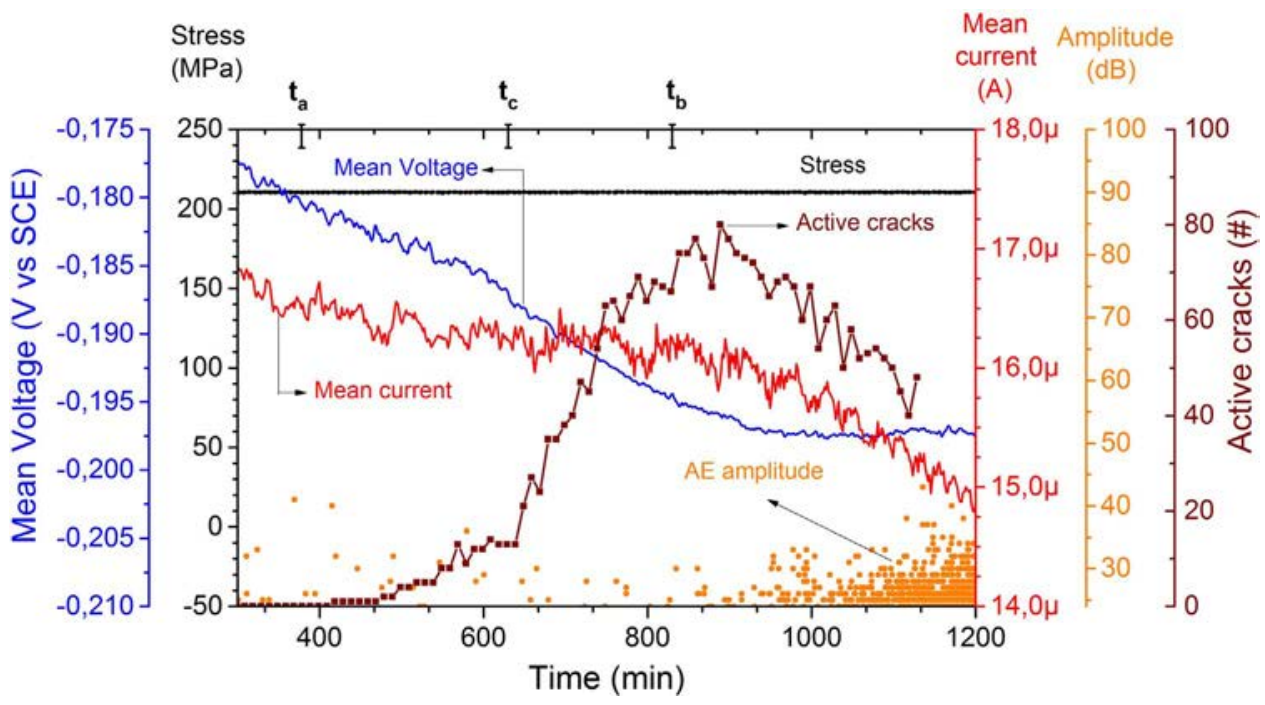

Fig. 11. Compilation of AE, EN and DIC data for the CC-03-15 test. 


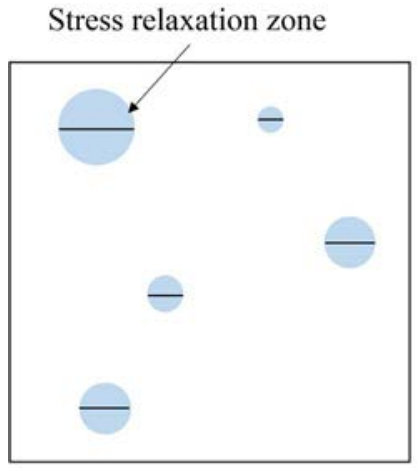

Short pre-immersion period
Crack

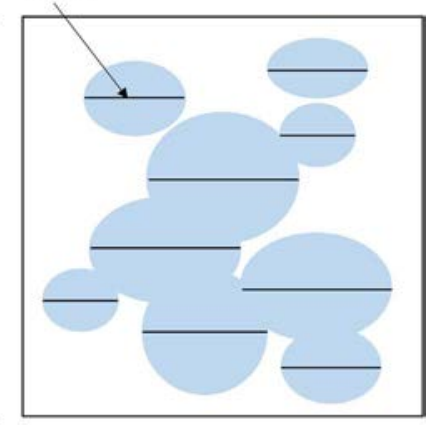

Long pre-immersion period
Fig. 12. Diagram of the stress relaxation zone produced by the apparition of a crack in the first stages according to different durations of pre-immersion.

Table 4

Trend of the main parameters for crack colony evolution in the CC 03-15 test

\begin{tabular}{|c|c|c|c|}
\hline & \multicolumn{3}{|l|}{ Stage } \\
\hline & $\begin{array}{l}\text { I } \\
\text { from } t_{a} \text { until } t_{c} \\
(378-658 \mathrm{~min})\end{array}$ & $\begin{array}{l}\text { II } \\
\text { from } t_{c} \text { until } t_{b} \\
(658-830 \mathrm{~min})\end{array}$ & $\begin{array}{l}\text { III } \\
\text { from } t_{b} \text { until the end } \\
(830-1130 \mathrm{~min})\end{array}$ \\
\hline Crack density & Increases & Increases sharply & Decreases \\
\hline $\begin{array}{l}\text { Initiation } \\
\text { kinetic }\end{array}$ & Low and constant & Increases & Low and constant \\
\hline $\begin{array}{l}\text { Active crack } \\
\text { population }\end{array}$ & + & +++ & ++ \\
\hline Mean CGR* & Slight increase & Constant & Slight decrease \\
\hline $\begin{array}{c}\text { Coalescence } \\
\text { kinetic }\end{array}$ & No coalescence & Increases sharply & Constant \\
\hline EPN level & Decreases & Decreases sharply & Constant \\
\hline ECN level & $\begin{array}{l}\text { High with a slight } \\
\text { diminution }\end{array}$ & $\begin{array}{l}\text { High with a slight } \\
\text { diminution }\end{array}$ & Decreases \\
\hline AE activity & Weak & Weak & Strong \\
\hline$\eta$ & Decreases & Decreases & Increases \\
\hline GCCGR & Increases & Increases sharply & Constant \\
\hline
\end{tabular}

*mean CGR does not take into account merging cracks.

colony.

Table 4 summarizes the principal crack colony parameters obtained for the CC 03-15 test, presented in Section 3. According to the results, the development of the crack colony can be separated into three stages.

In the first stage of the test (period between $t_{a}$ and $t_{c}$ ) it is observed that the majority of cracks are active (Fig. 9 and Table 4). Moreover, the mean CGR (Fig. 10 and Table 4) also exhibits an increasing trend which proves that the propagating cracks are not yet influenced by their environment. In addition, EN measurements confirm the high activity of the surface with a continuous decrease in EPN values, while the ECN DC-level remains high (Fig. 11). Furthermore, AE measurements display a low acoustic emission activity (Fig. 10). The low AE level suggests once again the occurrence of a significant dissolution process localized at grain boundaries. Indeed, it is known that such electrochemical processes hardly release enough energy to be detected $[52,61]$. Regarding the evolution of the aspect ratio " $\eta$ " (Fig. 10), it may be noted that " $\eta$ " displays a decrease in this first stage of the test (between $t_{a}$ and $t_{c}$ ) showing that cracks tend to propagate on the surface rather than into the bulk. Such behavior is different from crack propagation under mechanical load only. In the latter case, cracks with a smaller aspect ratio propagate in depth rather than on the surface from their first steps of development [23]. All of the above suggests that cracks initiate by IGA and start to grow as isolated cracks. Corrosion seems to play quite a large role in the propagation process, as was noted by the EN signals and by the feeble acoustic emission activity.

During the second stage of the crack colony propagation (between times $t_{c}$ and $t_{b}$ ), active cracks are dominant, compared to dormant and initiation populations (Fig. 9). The mean EPN displays a strong decrease while the mean ECN and AE activity is as in the first stage (Table 4). In addition, Fig. 8 shows that several coalescence events start to occur while the mean CGR, which excludes the effects of coalescences, remains constant. Such changes in the trend of the mean CGR reveal that the majority of cracks in the colony are no more propagating as isolated ones. On the contrary, interactions start to influence the global behavior of the colony. Such interactions include coalescences but also shielding effects. The decrease in the initiation kinetic close to time $t_{b}$ (Fig. 9) is a consequence of the shielding effect between cracks. As mentioned before, such a shielding effect is due to the emergence of the relaxation zone around the crack flanks. The superposition of the different relaxation zones, coming from the propagation of multiple cracks, induces a general de-stressing of the surface which also decreases the crack driving force (Fig. 12). The probability of a new crack to be initiated in such systems is highly dependent on the local stress which plays an important part in the rupture of the passive film. Stress relaxation decreases the probability of cracks initiating, hence the start of coalescences being more regular than initiations and the crack density finally decreases (Fig. 9) as already demonstrated by Kamaya et al. [23]. The shape factor " $\eta$ ", continues to decrease, showing that cracks are still propagating more on the surface rather than in depth (Fig. 11). As in stage I, corrosion is highly implicated in the propagation mechanism. Yet, even if some cracks start to feel the consequences of interactions; such interactions begin to barely influence the development of the colony.

In the last stage, defined from $t_{b}$ until the end of the test, active cracks continue to dominate the population but now have a tendency to decrease (crack density also decreases). This decreasing trend is also encountered in the ECN signal and can be related to the propagation of active cracks. At this stage, there are fewer propagating active cracks. Therefore, the variations in the crack front of active cracks become less intensive and the amount of metal dissolution also decreases, inducing a decrease in the DC level of current. On the other hand, EPN shows also a drop in the first part and then stabilizes at around $-195 \mathrm{mV} / \mathrm{SCE}$ (Fig. 11). Stabilization could be attributed to the propagation of few dominant cracks where a continuous bare metal surface at the crack tip is being generated. Regarding AE activity, acoustic bursts start to be significant some minutes after time $t_{b}$. Such activity seems to be related to the intensification of interactions which is expected to produce more confined plastic deformation on the approaching crack tips. Indeed coalescence processes are governed by mechanics [62]. The effects of shielding on the surface are confirmed by the decrease in the average CGR from $t_{b}$ (Fig. 8). Coalescences also become less intensive, but are still effective. In addition, the aspect form " $\eta$ " displays a change in its evolution around $t_{b}$, implying that cracks start to grow more in volume than in surface. Such behavior can explain why the coalescence rate slows down too; it is thought that at around $t_{b}$, the shielding effect between cracks is enough to prevent crack propagation at the surface, and therefore enhances crack propagation in the depth direction.

Taking into consideration all of the above, both AE and EN measurements suggest a propagation mechanism of cracks by the continuous anodic dissolution of the crack front. This dissolution process greatly decreases the tenacity of the material and promotes continuous crack propagation. The crack front tip becomes weak enough to be fractured by stress without any important plastic deformation. Therefore, no significant AE activity is detected and cracks grow in surface with shallow features. The influence of interactions starts to have effects on the global behavior of the colony at around $800 \mathrm{~min}$. At this time, cracks start to display a tendency to grow in depth; interactions take control of colony growth and the shielding effect between cracks starts to produce plastic deformation at the crack tip. The increase in local deformation together with coalescence events involving larger and larger cracks, are thought to explain the increase in $\mathrm{AE}$ activity. 


\section{Conclusions}

An in-situ experimental configuration was designed for the study by DIC of the behavior of multiple stress corrosion cracks. Intergranular crack colonies with a very brittle aspect and low levels of plastic strain were obtained.

An in-house data treatment routine was specially developed for the identification, classification and monitoring of cracks. Cracks exceeding $55 \mu \mathrm{m}$ and opened more than $0.45 \mu \mathrm{m}$ could be detected. In addition, the crack population was classified into initiating, active and dormant cracks. The evolution, with time, of each population was obtained. Crack interactions such as coalescence and shielding were also registered.

Correlations between DIC, EN and AE results enabled us to sort crack colony propagation into 3 stages. The lack of acoustic emissions accompanied by high levels of current (DC part) in the first part of the test, suggest that active dissolution and lack of re-passivation are responsible for crack advance, which remains at the surface and involves very few interactions. In the second stage, interactions between cracks (coalescence + shielding) begin to occur but don't modify the general behavior of the colony, whose growth remains mainly governed by active anodic dissolution. Subsequently, the intensification of interactions leads to a decrease in the number of active cracks and the crack growth rate. Mechanical factors (local stresses and strain) become then the main driving force for crack propagation which principally affects crack depth.

To close, the quantitative experimental data used (initiation kinetics, crack growth rate, coalescence number, crack geometry etc.), will now be used for developing a numerical simulation of SCC colony growth and attain more reliable lifetime predictions. The same experimental approach will also be extended to the case of transgranular SCC, and in even more severe conditions of temperature and pressure.

\section{Acknowledgements}

The authors would like to acknowledge the National French Research Agency (ANR) for its financial support under contract MATETPRO ANR-12-RMNP-0020 (ECCOFIC project). The authors would like also to thank our partners AREVA, ANDRA and MISTRAS by their participation into the fruitful discussion during this work.

\section{References}

[1] P. Marcus, Corrosion Mechanisms in Theory and Practice, C R C Press LLC Taylor \& Francis Group [Distributor], Boca Raton; Florence, 2002.

[2] Bamford, Hall, A review of alloy 600 cracking on operating nuclear plants including alloy 82 and 182 weld behavior, Proc. of ICONE12, ASME (2004).

[3] D.W. Alley, A regulatory analysis and perspective regarding degradation of materials in light water reactors, Proc. of Corrosion 2011, Paper No. 11198, NACE (2011).

[4] P.M. Scott, 2000 FN speller award lecture: stress corrosion cracking in pressurized water reactors-interpretation, modeling, and remedies, Corrosion 56 (8) (2000) $771-782$.

[5] C. Bataille, C. Birraux, La Durée De Vie Des Centrales Nucleaires Et Les Nouveaux Types De Reacteurs 832 Assamblée Nationale Française, 2003.

[6] S. Mohanty, S. Majumdar, K. Natesan, A Review of Stress Corrosion Cracking/ Fatigue Modeling for Light Water Reactor Cooling System Components, (2012).

[7] T.H. Leek, I.C. Howard, An examination of methods of assessing interacting surface cracks by comparison with experimental data, Int. J. Press. Vessels Pip. 68 (2) (1996) 181-201.

[8] M. Kamaya, T. Haruna, Crack initiation model for sensitized 304 stainless steel in high temperature water, Corros. Sci. 48 (9) (2006) 2442-2456.

[9] Y.-Z. Wang, K. Ebtehaj, D. Hardie, R.N. Parkins, The behaviour of multiple stress corrosion cracks in a Mn-Cr and a Ni-Cr-Mo-V steel: i-Metallography, Corros. Sci. 37 (11) (1995) 1651-1675.

[10] T.H. Leek, I.C. Howard, Rules for the assessment of interacting surface cracks under mode I load, Int. J. Press. Vessels Pip. 60 (3) (1994) 323-339.

[11] T.H. Leek, I.C. Howard, Estimating the elastic interaction factors of two coplanar surface cracks under mode I load, Int. J. Press. Vessels Pip. 60 (3) (1994) 307-321.

[12] Y.-Z. Wang, K. Ebtehaj, D. Hardie, R.N. Parkins, The behaviour of multiple stress corrosion cracks in a Mn-Cr and a Ni-Cr-Mo-V steel: II-statistical characterisation, Corros. Sci. 37 (11) (1995) 1677-1703.
[13] D. Féron (Ed.), Corrosion Issues in Light Water Reactors: Stress Corrosion Cracking, CRC Press, Boca Raton, Fla, 2007.

[14] A.A. Griffith, The phenomena of rupture and flow in solids, Phil. Trans. R. Soc. Lond. A 221 (1921) 163-198.

[15] Y.-Z. Wang, J.D. Atkinson, R. Akid, R.N. Parkins, Crack interaction, coalescence and mixed mode fracture mechanics, Fatigue Fract. Eng. Mater. Struct. 19 (4) (1996) 427-439.

[16] Y. Ochi, A. Ishii, S.K. Sasaki, An experimental and statistical investigation of surface fatigue crack initiation and growth, Fatigue Fract. Eng. Mater. Struct. 8 (4) (1985) $327-339$.

[17] P.J.E. Forsyth, A unified description of micro and macroscopic fatigue crack behaviour, Int. J. Fatigue 5 (1) (1983) 3-14.

[18] R.N. Parkins, P.M. Singh, Stress corrosion crack coalescence, Corrosion 46 (6) (1990) 485-499.

[19] T. Winkler, A. Brückner-Foit, H. Riesch-Oppermann, Statistical characterization of random crack patterns caused by thermal fatigue, Fatigue Fract. Eng. Mater. Struct. 15 (10) (1992) 1025-1039.

[20] H. Kitagawa, T. Fujita, K. Miyazawa, Small Randomly Distributed Cracks in Corrosion Fatigue, Philadelphia STP 624 (1978), pp. 98-114.

[21] M. Kamaya, A crack growth evaluation method for interacting multiple cracks, JSME Int. J. Ser. A 46 (1) (2003) 15-23.

[22] M. Kamaya, T. Haruna, Influence of local stress on initiation behavior of stress corrosion cracking for sensitized 304 stainless steel, Corros. Sci. 49 (8) (2007) 3303-3324.

[23] Y. Murakami, S. Nemat-Nasser, Interacting dissimilar semi-elliptical surface flaws under tension and bending, Eng. Fract. Mech. 16 (3) (1982) 373-386.

[24] H. Nisitani, Y. Murakami, Stress intensity factors of an elliptical crack or a semielliptical crack subject to tension, Int. J. Fract. 10 (3) (1974) 353-368.

[25] P.E. O'Donoghue, Analysis of Interaction Behavior of Surface Flaws in Pressure Vessels, (1986)

[26] P.E. O’Donoghue, T. Nishioka, S.N. Atluri, Multiple surface cracks in pressure vessels, Eng. Fract. Mech. 20 (3) (1984) 545-560.

[27] M. Kamaya, N. Totsuka, Influence of interaction between multiple cracks on stress corrosion crack propagation, Corros. Sci. 44 (10) (2002) 2333-2352.

[28] M. Kamaya, Influence of the interaction on stress intensity factor of semielliptical surface cracks, J. Press. Vessel Technol. 130 (1) (2008) 011406.

[29] Y.-Z. Wang, D. Hardie, R.N. Parkins, The behaviour of multiple stress corrosion cracks in a Mn-Cr and a Ni-Cr-Mo-V steel: III-Monte Carlo simulation, Corros. Sci. 37 (11) (1995) 1705-1720.

[30] J.A. Duff, T.J. Marrow, In situ observation of short fatigue crack propagation in oxygenated water at elevated temperature and pressure, Corros. Sci. 68 (2013) $34-43$.

[31] T.C. Chu, W.F. Ranson, M.A. Sutton, Applications of digital-image-correlation techniques to, Exp. Mech. 25 (3) (1985) 232-244.

[32] D.J. Wu, W.G. Mao, Y.C. Zhou, C. Lu, Digital image correlation approach to cracking and decohesion in a brittle coating/ductile substrate system, Appl. Surf. Sci. 257 (14) (2011) 6040-6043

[33] J.R. Yates, M. Zanganeh, Y.H. Tai, Quantifying crack tip displacement fields with DIC, Eng. Fract. Mech. 77 (11) (2010) 2063-2076.

[34] J. Quinta Da Fonseca, P.M. Mummery, P.J. Withers, Full-field strain mapping by optical correlation of micrographs acquired during deformation, J. Microsc. 218 (1) (2005) 9-21.

[35] S. Rahimi, D.L. Engelberg, J.A. Duff, T.J. Marrow, In situ observation of intergranular crack nucleation in a grain boundary controlled austenitic stainless steel, J. Microsc. 233 (2009) 423-431.

[36] J.A. Duff, T.J. Marrow, In-situ observations of intergranular stress corrosion cracking, ASME 2008 Pressure Vessels and Piping Conference (2008) 847-854.

[37] A. Stratulat, J.A. Duff, T.J. Marrow, Grain boundary structure and intergranular stress corrosion crack initiation in high temperature water of a thermally sensitised austenitic stainless steel, observed in situ, Corros. Sci. 85 (2014) 428-435.

[38] E. Durif, M. Fregonese, J. Réthoré, A. Combescure, C. Alemany-Dumont, Methodology for a mechano-electrochemical evaluation of the coupling at the crack tip. Application of halide-induced Stress Corrosion Cracking of Zircaloy-4, Corros. Sci. 93 (2015) 39-47.

[39] J.A. Duff, T.J. Marrow, In situ observation of short fatigue crack propagation in oxygenated water at elevated temperature and pressure, Corros. Sci. 68 (2013) $34-43$

[40] N. Duff, S. Stevens, A. Lyon Sherry, J. Marrow, Preliminary Evaluation of Digital Image Correlation for In-situ Observation of Low Temperature AtmosphericInduced Chloride Stress Corrosion Cracking in Austenitic Stainless Steels, (2010), pp. 119-132.

[41] J. Kovac, C. Alaux, T.J. Marrow, E. Govekar, A. Legat, Correlations of electro chemical noise, acoustic emission and complementary monitoring techniques during intergranular stress-corrosion cracking of austenitic stainless steel, Corros. Sci. 52 (6) (2010) 2015-2025.

[42] L. Calabrese, L. Bonaccorsi, M. Galeano, E. Proverbio, D. Di Pietro, F. Cappuccini, Identification of damage evolution during SCC on $17-4 \mathrm{pH}$ stainless steel by combining electrochemical noise and acoustic emission techniques, Corros. Sci. 98 (2015) 573-584.

[43] G. Du, J. Li, W.K. Wang, C. Jiang, S.Z. Song, Detection and characterization of stress-corrosion cracking on 304 stainless steel by electrochemical noise and acoustic emission techniques, Corros. Sci. 53 (9) (2011) 2918-2926.

[44] J. Kovač, M. Leban, A. Legat, An attempt to detect SCC by combined measurements of electrochemical noise and acoustic emission, Mater. Corros. 58 (12) (2007) 970-976.

[45] S. Ritter, H.-P. Seifert, Detection of SCC initiation in austenitic stainless steel by 
electrochemical noise measurements, Mater. Corros. 64 (8) (2013) 683-690.

[46] M. Breimesser, S. Ritter, H.-P. Seifert, S. Virtanen, T. Suter, Application of the electrochemical microcapillary technique to study intergranular stress corrosion cracking of austenitic stainless steel on the micrometre scale, Corros. Sci. 55 (2012) $126-132$.

[47] M. Leban, Ž. Bajt, A. Legat, Detection and differentiation between cracking processes based on electrochemical and mechanical measurements, Electrochim. Acta 18 (2004) 2795-2801.

[48] M. Breimesser, S. Ritter, H.-P. Seifert, T. Suter, S. Virtanen, Application of elec trochemical noise to monitor stress corrosion cracking of stainless steel in tetrathionate solution under constant load, Corros. Sci. 63 (2012) 129-139.

[49] M. Akbari, M. Ahmadi, The application of acoustic emission technique to plastic deformation of low carbon steel, Phys. Procedia 3 (1) (2010) 795-801.

[50] A.O. Amer, A.-L. Gloanec, S. Courtin, C. Touze, Characterization of fatigue damage in 304L steel by an acoustic emission method, Procedia Eng. 66 (2013) 651-660.

[51] S. Yuyama, Fundamental Aspects of Acoustic Emission Applications to the Problems Caused by Corrosion, Presented at the Corrosion Monitoring in Industrial Plants Using Nondestructive Testing and Electrochemical Methods, Philadelphia ASTM STP 908 (1986), pp. 43-74.

[52] M.G. Alvarez, P. Lapitz, J. Ruzzante, AE response of type 304 stainless steel during stress corrosion crack propagation, Corros. Sci. 50 (12) (2008) 3382-3388.

[53] M.G. Alvarez, P. Lapitz, J. Ruzzante, Analysis of acoustic emission signals generated from SCC propagation, Corros. Sci. 55 (2012) 5-9.
[54] J. Xu, E.-H. Han, X. Wu, Acoustic emission response of 304 stainless steel during constant load test in high temperature aqueous environment, Corros. Sci. 63 (2012) 91-99.

[55] L. Djeddi, R. Khelif, S. Benmedakhene, J. Favergeon, Reliability of acoustic emission as a technique to detect corrosion and stress corrosion cracking on prestressing steel strands, Int. J. Electrochem. Sci. 8 (2013) 8356-8370.

[56] G. Besnard, F. Hild, S. Roux, 'Finite-Element' displacement fields analysis from digital images: application to Portevin-Le Châtelier bands, Exp. Mech. 46 (6) (2006) 789-803.

[57] J.E. Hack, G.R. Leverant, On the prediction of the surface crack opening displacement of a part through crack, Int. J. Fract. 16 (1) (1980) R15-R18.

[58] H.H. Horowitz, Chemical studies of polythionic acid stress-corrosion cracking, Corros. Sci. 23 (4) (1983) 353-362.

[59] R. Bandy, R. Roberge, R.C. Newman, Low temperature stress corrosion cracking of Inconel 600 under two different conditions of sensitization, Corros. Sci. 23 (9) (1983) 995-1006.

[60] G.S. Was, V.B. Rajan, The mechanism of intergranular cracking of Ni-Cr-Fe alloys in sodium tetrathionate, Metall. Trans. A 18 (7) (1987) 1313-1323.

[61] J. Xu, X. Wu, E.-H. Han, Acoustic emission response of sensitized 304 stainless steel during intergranular corrosion and stress corrosion cracking, Corros. Sci. 73 (2013) 262-273.

[62] R.N. Parkins, P.M. Singh, Stress corrosion crack coalescence, Corrosion 46 (6) (1990) 485-499. 